\title{
Relationship between C-reactive protein levels and obstructive sleep apnea syndrome
}

\author{
Y.X. Tie, Y.Y. Fu, Z. Xu and Y. Peng \\ Department of Respiratory Medicine, Xinxiang Central Hospital, \\ Xinxiang, China \\ Corresponding author: Y.Y. Fu \\ E-mail: fyfadber_wer35@163.com
}

Genet. Mol. Res. 15 (2): gmr.15027808

Received October 8, 2015

Accepted November 24, 2015

Published May 25, 2016

DOI http://dx.doi.org/10.4238/gmr.15027808

\begin{abstract}
This study aims to determine the relationship between C-reactive protein levels and obstructive sleep apnea syndrome (OSAS). We recruited 30 OSAS patients into the observation group (OSAS group), and subdivided them into mild, moderate and severe groups according to the apnea hypopnea index. In addition, 20 normal individuals were included in the control group. Plasma CRP levels of two groups were measured. As compared with the control group, the CRP levels in the OSAS group were significantly increased $(\mathrm{P}<$ 0.05). ANOVA showed that CRP levels in the three subgroups differ; statistically significant differences between the mild and severe OSA patients were observed $(\mathrm{P}<0.05)$. It was hypothesized that OSAS patients show elevated serum CRP levels, and that serum CRP levels are associated with OSAS severity.
\end{abstract}

Key words: C-reactive protein; Obstructive sleep apnea syndrome 


\section{INTRODUCTION}

Obstructive sleep apnea (OSA) is the most common type of sleep apnea, and is caused by partial or complete occlusion of the upper airway during sleep. This is accompanied by hypoxia and repeated awareness-induced sleep discontinuities. Clinical studies have shown that OSA is related to the occurrence and development of atherosclerosis and cardiovascular diseases (Young et al., 2008), which are risk factors for hypertension, abdominal obesity, dyslipidemia, and other diseases. Related studies have also demonstrated that OSA is associated with insulin resistance (also known as abnormal glucose tolerance) (Yaggi et al., 2006). It has been suggested that even slight increases in the apnea hypopnea index (AHI) can lead to increased mortality from cardiovascular diseases. Inflammation plays a fundamental role in the development of atherosclerosis (Kokturk et al., 2005), and the inflammatory marker C-reactive protein (CRP) can be used as a potential diagnostic tool. Studies have demonstrated that in individuals with coronary atherosclerotic heart disease, diabetes, hypertension, or those that smoke, CRP is increased as compared with that in the normal population. In this study, the relationship between plasma CRP levels and OSA was investigated.

\section{MATERIAL AND METHODS}

\section{General information}

OSAS patients admitted into the Respiratory Medicine of Xinxiang Central Hospital from December 2011 to December 2012 were diagnosed with polysomnographic monitoring, which was in line with the relevant standards developed by the RDDS group of Chinese Thoracic Society in 2011 (2012). A total of 30 patients, 21 males and 9 females, were recruited into the observation group, and ranged between 38 and 75 years of age (mean $=68.27 \pm 8.32$ years). According to the apnea hypopnea index (AHI), the patients were further subdivided into the mild (AHI 5-15 times / h, 10 cases), the moderate (AHI 16-30 times/h, 11 cases), and the severe subgroups (AHI 31 times/h, 9cases). We also enrolled 20 normal individuals, including 14 males and 6 females, into the control group. These individuals showed normal polysomnography $(\mathrm{AHI}<5$ times $/ \mathrm{h}$ ), and were between 41 and 71 years of age (mean $=56.30$ \pm 8.52 years). Patients with clear infectious diseases, chronic diseases, immune diseases, hypertension, diabetes, thyroid diseases, and hospitalization records four weeks prior to study onset were excluded.

\section{Methods}

\section{Sleep apnea monitoring}

Sleep apnea was monitored using the YH-2000A polysomnographic monitor, which was provided by the Beijing YIHEJIAYE Technology Research Center. Sleep in study subjects was continuously monitored for $7 \mathrm{~h}$ overnight; electrocephalogram (EEG), electromyography (EMG) of the eye, electrocardiogram (ECG), nasal airflow pressure, posture, pulse oximetry, snoring, and leg movements were recorded. During the day of sleep monitoring, tea, coffee, liqueur, and sedative, hypnotic drugs were prohibited. 


\section{Serum CRP detection}

Fasting venous blood $(5 \mathrm{~mL})$ was collected between 7:00 - 8:00 a.m. after polysomnographic monitoring, and was stored at $-20^{\circ} \mathrm{C}$. Serum CRP was quantified via latex turbidimetric immunoassay using the C-reactive protein detection kit (Spanish Biosystems S.A. Company) and the DXC800 automatic biochemical analyzer (USA).

\section{Statistical methods}

Data were analyzed with the SPSS13.0 statistical software. CRP values are reported as means $\pm \mathrm{SE}$, and comparisons between groups were performed using the Student $t$-test. Count data are repored as the number of cases $(\mathrm{N})$; comparison of rate $(\%)$ was calculated using the $\chi^{2}$ test; $\mathrm{P}<0.05$ was considered to be statistically significant.

\section{RESULTS}

Serum CRP $(5.33 \pm 2.11 \mathrm{mg} / \mathrm{L})$ in the OSAS group was found to be significantly higher as compared with the control group $(2.35 \pm 0.90 \mathrm{mg} / \mathrm{L})(\mathrm{P}<0.01$, Figure 1$)$. There were no significant differences in age, body weight, heart rate, mean arterial pressure and BMI between the two groups (Table 1).

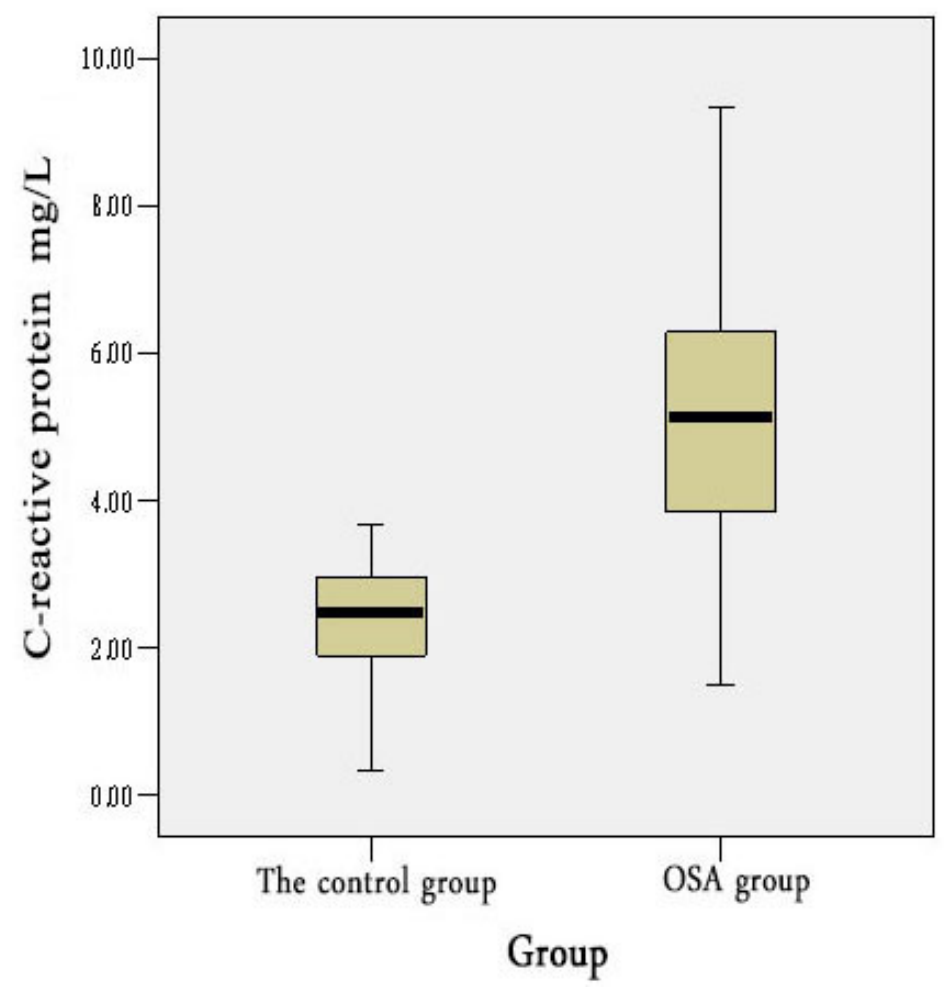

Figure 1. Comparison of CRP levels between the OSA and control groups $(\mathrm{P}<0.0001)$. 
Table 1. Clinical data in treatment group and control groups.

\begin{tabular}{l|c|c|c}
\hline Indicators & Observation group $(\mathrm{N}=30)$ & Control group $(\mathrm{N}=20)$ & P value \\
\hline Age $($ years $)$ & $68.27 \pm 8.32$ & $56.30 \pm 8.52$ & 0.42 \\
\hline body weight $(\mathrm{kg})$ & $79.57 \pm 11.54$ & $74.07 \pm 6.95$ & 0.06 \\
\hline heart rate $(/ \mathrm{min})$ & $74.22 \pm 11.39$ & $72.37 \pm 7.78$ & 0.53 \\
\hline mean arterial pressure $(\mathrm{mmHg})$ & $83.06 \pm 8.19$ & $81.95 \pm 9.26$ & 0.66 \\
\hline $\mathrm{BMI}\left(\mathrm{kg} / \mathrm{m}^{2}\right)$ & $26.61 \pm 2.22$ & $25.73 \pm 2.72$ & 0.21 \\
\hline $\mathrm{CRP}(\mathrm{mg} / \mathrm{L})$ & $5.33 \pm 2.11$ & $2.35 \pm 0.90$ & 0.00 \\
\hline
\end{tabular}

\section{Plasma CRP comparison among the mild, moderate and severe OSA subgroups}

Results from ANOVA analysis showed that serum CRP levels in the three subgroups differ $(\mathrm{F}=3.93, \mathrm{P}=0.03)$. Paired comparison indicated that no statistical difference between the mild and the moderate OSA subgroups $(\mathrm{P}=0.140)$, or the moderate and severe subgroups $(\mathrm{P}=0.178)$. However, CRP levels were significantly different between the mild group and severe OSA subgroup $(\mathrm{P}=0.009)$.

\section{DISCUSSION}

C-reactive protein is an annular, pentameric protein found in the blood plasma, and is a nonspecific marker of inflammation. It is synthesized by the liver, and is regulated by interleukin-6 (IL-6) as well as other cytokines. Generally, plasma C-reactive protein level remains relatively stable, and is a reflection of the inflammatory state of the body over the past $24 \mathrm{~h}$. Epidemiological studies have shown that elevated C-reactive protein level is a strong predictor of cardiovascular diseases in the healthy population (Meier-Ewert et al., 2001). Several large trials have also demonstrated that elevated level of C-reactive protein is an independent risk factor of acute myocardial infarction, stroke, and peripheral vascular diseases (Ridker et al., 2001). Existing evidence suggests that atherosclerosis represents a chronic inflammatory process, and a high concentration of C-reactive protein has been found in atherosclerotic lesions (Danesh et al., 2000). C-reactive protein is not only a prognostic indicator of cardiovascular diseases, but also plays a role in the development of atherosclerosis and endothelial dysfunctions. OSA manifestations include apnea-associated snoring during sleep and daytime sleepiness. Apnea can cause repeated episodes of nocturnal hypoxemia and hypercapnia, leading to complications such as hypertension, coronary heart disease, diabetes, cerebrovascular diseases, and even sudden death at night. Therefore, OSA is a potentially fatal sleep-respiratory disease.

At present, the relationship between CRP levels and OSA remains controversial. In this study, we found that CRP levels in the OSA patients were significantly higher as compared with that in normal individuals. Furthermore, significant differences in CRP levels were detected between mild and severe OSA patients, similar to findings by Roche et al. (2009). Previous studies have also found that plasma CRP and IL-6 levels were elevated in patients with OSA. With continuous positive airway pressure ventilation, OSA symptoms were improved with decreased CRP and IL-6 levels, suggesting that CRP levels may be associated with OSA severity. However, Guilleminault et al. (2004) found that CRP was not associated with severity of OSA, and Kaditis et al. (2005) stated that CRP levels in children were independent of OSA.

Currently, it is believed that the mechanisms underlying OSA-induced elevation in CRP levels include repeated hypoxic stress and sleep deprivation. These factors can lead to 
release of cytokines and activation of neutrophils, monocytes, as well as other inflammatory cells. The morbidity and mortality rates of atherosclerosis and cardiovascular diseases are also elevated in OSA patients (Lui et al., 2009). The mechanisms underlying such associations may be due to repeated hypoxia and systemic inflammation, which can induce increased sympathetic activity and endothelial dysfunction.

In summary, OSA patients have greater incidences of cardiovascular disease related mortality. However, the association between OSA and obesity, insulin resistance, age, alcohol intake, or smoking is still unknown. Related studies have shown that CRP plays a prognostic role in the occurrence of cardiovascular disease in the healthy population. The detection of CRP levels will allow timely treatments of OSA to be administered. In addition, investigation of CRP levels will further enable us to determine whether OSA is associated with conditions such as cardiovascular diseases, cerebrovascular disease, and diabetes.

\section{Conflicts of interest}

The authors declare no conflicts of interest.

\section{ACKNOWLEDGMENTS}

Research supported by the Xinxiang Scientific and Technological Projects (\#ZG12020).

\section{REFERENCES}

Danesh J, Whincup P, Walker M, Lennon L, et al. (2000). Low grade inflammation and coronary heart disease: prospective study and updated meta-analyses. BMJ 321: 199-204. http://dx.doi.org/10.1136/bmj.321.7255.199

Guilleminault C, Kirisoglu C and Ohayon MM (2004). C-reactive protein and sleep-disordered breathing. Sleep 27: $1507-$ 1511.

Kokturk O, Ciftci TU, Mollarecep E and Ciftci B (2005). Elevated C-reactive protein levels and increased cardiovascular risk in patients with obstructive sleep apnea syndrome. Int. Heart J. 46: 801-809. http://dx.doi.org/10.1536/ihj.46.801

Kaditis AG, Alexopoulos EI, Kalampouka E, Kostadima E, et al. (2005). Morning levels of C-reactive protein in children with obstructive sleep-disordered breathing. Am. J. Respir. Crit. Care Med. 171: 282-286. http://dx.doi.org/10.1164/ rccm.200407-9280C

Lui MM, Lam JC, Mak HK, Xu A, et al. (2009). C-reactive protein is associated with obstructive sleep apnea independent of visceral obesity. Chest 135: 950-956. http://dx.doi.org/10.1378/chest.08-1798

Meier-Ewert HK, Ridker PM, Rifai N, Price N, et al. (2001). Absence of diurnal variation of C-reactive protein concentrations in healthy human subjects. Clin. Chem. 47: 426-430.

Ridker PM, Stampfer MJ and Rifai N (2001). Novel risk factors for systemic atherosclerosis: a comparison of C-reactive protein, fibrinogen, homocysteine, lipoprotein(a), and standard cholesterol screening as predictors of peripheral arterial disease. JAMA 285: 2481-2485. http://dx.doi.org/10.1001/jama.285.19.2481

Roche F, Gaspoz JM, Pichot V, Picard-Kossovsky M, et al.; PROOF and SYNAPSE Study Groups (2009). Association between C-reactive protein and unrecognised sleep-disordered breathing in the elderly. Eur. Respir. J. 33: 797-803. http://dx.doi.org/10.1183/09031936.00023208

Yaggi HK, Araujo AB and McKinlay JB (2006). Sleep duration as a risk factor for the development of type 2 diabetes. Diabetes Care 29: 657-661. http://dx.doi.org/10.2337/diacare.29.03.06.dc05-0879

Young T, Finn L, Peppard PE, Szklo-Coxe M, et al. (2008). Sleep disordered breathing and mortality: eighteen-year follow-up of the Wisconsin sleep cohort. Sleep 31: 1071-1078. 